\title{
A judicialização da política no Brasil e a atuação do assistente social na justiça
}

\author{
Vânia Morales Sierra \\ Universidade do Estado do Rio de Janeiro (UERJ)
}

\begin{abstract}
A judicialização da política no Brasil e a atuação do assistente social na justiça
Resumo: A judicialização no Brasil tem rebatido nas políticas sociais, incidindo diretamente sobre as formas de gestão da questão social. Trata-se de uma tendência que se acentua na democracia brasileira, num contexto de avanço da política neoliberal. Este artigo tem o objetivo de contribuir para o debate acerca da judicialização da política e da questão social no Brasil, com destaque à mudança no papel do Poder Judiciário e à atuação do Serviço Social no sociojurídico. A relevância para o Serviço Social se faz por sua contribuição na tarefa de tornar a justiça mais substantiva. Este trabalho tem implicações éticas, pois ao mesmo tempo em que se inclina em defesa da cidadania, numa perspectiva promocional do direito, também serve ao aperfeiçoamento dos mecanismos de controle social.
\end{abstract}

Palavras-chave: Judicialização da política. Questão social. Assistente social. Serviço Social.

\section{The Treatment of Policies in the Courts in Brazil and the Action of Social Workers in Justice}

Abstract: The increased use of the judicial system for resolution of social issues in Brazil has had repercussions on social policies and directly affects the administration of social issues. This is a trend that stands out in Brazilian democracy, in the context of the advance of neoliberal policies. The purpose of this article is to contribute to the debate about the treatment of policies in the courts and the social question in Brazil, highlighting the change in the role of the judiciary and the action of Social Work in socio-juridical issues. The relevance for Social Work is due to its contribution to the task of making justice more substantive. This work has ethical implications, because at the same time that it leans towards a defense of citizenship, from a perspective that promotes rights, it also serves to perfect social control mechanisms.

Key words: Treating policy issues in the courts. Social issues. Social worker. Social Work. 


\section{Introdução}

A judicialização das políticas públicas pode ser entendida como o aumento desmesurado de ações judiciais movidas por cidadãos que cobram o direito à proteção social. No Brasil, este processo deslanchou após a promulgação da Constituição de 1988 (BRASIL, 1999), que não apenas positivou os direitos fundamentais, mas também atribuiu ao Poder Judiciário a função de intérprete do controle de constitucionalidade ${ }^{1}$. As implicações políticas e sociais oriundas destas mudanças tendem a alterar significativamente a cultura jurídica nacional, até então moldada pelo formalismo legalista e pela subordinação do Poder Judiciário ao Poder Executivo. A adaptação do direito brasileiro à perspectiva federalista, que adota o sistema de pesos e contrape$\operatorname{sos}^{2}$, supõe a existência de um Poder Judiciário mais independente, capaz de exercer um papel ativo, com base numa prática judiciária, que requer a interpretação do texto constitucional. Não obstante os avanços que podem ser alcançados no sentido da defesa da cidadania, estas modificações não servem apenas à redemocratização da sociedade, elas respondem também à necessidade de intervenção do Poder Judiciário frente às novas tendências da globalização e ao avanço da política neoliberal.

No Brasil, a constituição do Estado de direito e sua capacidade de garantir os direitos constitucionais vêm sendo colocada em xeque em decorrência dos processos de internacionalização da economia, que têm subordinado os Estados aos interesses de instituições e de organizações internacionais. $\mathrm{O}$ ajuste estrutural requerido pelas agências financeiras multilaterais, adotado ao longo da década de 1990, teve por efeito o aumento alarmante dos índices de desemprego e de violência nas cidades. Neste contexto, mesmo sem conseguir responder minimamente às necessidades sociais, novos estatutos foram criados, na expectativa de que o Poder Executivo viesse assumir a sua responsabilidade na efetivação dos direitos sociais. Não, por acaso, o tema da governabilidade tornara-se uma preocupação central dos governos, que passaram a relacionar a escassez de políticas públicas a uma questão de gestão, alegando a existência de limitações em sua capacidade financeira e administrativa para dar respostas às mais diversas reivindicações. Em outras palavras, alegavase a inviabilidade da efetivação dos direitos definidos constitucionalmente devido à explosão das demandas sociais. Por sua vez, as medidas para solucionar a chamada crise do Estado não ocorriam no sentido de melhor atender a estas demandas, pelo contrário, o governo passara a reduzir o gasto público, liquidando os sistemas de proteção social.

Em grande parte o fenômeno da judicialização das políticas públicas pode ser compreendido a partir desta contradição que expressa, por um lado, a existência de uma inflação de direitos, mas que, por outro, de- grada a proteção social. Este fenômeno tem trazido o Poder Judiciário à cena política, alterando a dinâmica da relação entre os Poderes. Em parte, tal processo resulta do êxito das lutas dos movimentos sociais em prol dos direitos humanos, que passaram a envolver as demandas de segmentos minoritários. Desde então, os direitos definidos pelos novos estatutos têm servido como referência para a elaboração de programas, que incorporam a linguagem do Direito numa perspectiva de defesa da cidadania pela valorização da autonomia, da participação no controle social e do reconhecimento das identidades grupais.

Nos diplomas legais, é o reconhecimento como sujeitos de direitos, que possibilita a conciliação entre direitos econômicos, sociais e culturais. Esta combinação tem alterado as concepções de justiça social, bem como as formas de intervenção do Estado, que vão se efetuando não mais pela referência ao trabalho, antes tida como base para proteção social, mas pela inserção dos sujeitos, por sua condição de ser, reconhecida no direito. Ao incorporar o sentido do pluralismo, as políticas sociais vão deixando de ser concebidas como um conjunto de medidas criadas para corrigir os efeitos do mercado, ou mesmo como objeto de reprodução da estrutura de classe, para serem percebidas como políticas de identidade ou de reconhecimento ${ }^{3}$, cujo principal objetivo é a promoção da igualdade de oportunidades, seguindo, portanto, o paradigma liberal. Como estas políticas são formuladas e executadas por decretos e leis, este modelo, que teve início na década de 1980, encontrou suporte no Poder Judiciário.

O envolvimento do Poder Judiciário na execução das políticas públicas trouxe uma série de implicações com o reconhecimento dos direitos de grupos sociais, pela opção de requerer judicialmente a consideração com a privação material a que estão submetidos. Daí a tendência à invasão no Poder Judiciário por aqueles que, sem condições para recorrer aos serviços no mercado, não conseguem garantir seus direitos pelo acesso às políticas do governo. Neste sentido, o processo de judicialização merece destaque entre os assistentes sociais visto incidir diretamente sobre as formas de gestão da questão social.

O tema da judicialização da política é polêmico e se expressa em pelo menos dois sentidos nas ciências sociais: ora sendo compreendido como um movimento que representa a continuidade da utilização do direito como fetiche, nada mais que uma racionalização ideológica, que legitima a exploração capitalista; ora sendo percebido como uma conquista da sociedade na defesa da cidadania nas democracias contemporâneas. Um dos motivos de intensificação da judicialização da política é a judicialização da questão social. Enquanto a primeira remete à intromissão do Poder Judiciário nos processos de deliberação política, admitindo com isso o conflito na relação entre os Poderes; 
a segunda refere-se ao aumento da interferência dos aparatos de controle judicial sobre a pobreza, quer seja para proteção e defesa dos direitos de cidadania, quer seja para repressão dos comportamentos penalmente puníveis. A temática apresenta-se relevante, visto que afeta de forma contraditória a vida social e política, ampliando inclusive o espaço de intervenção do Serviço Social. A análise acerca de suas implicações é o objetivo proposto neste artigo.

\section{A judicialização da política e da questão social no Brasil}

A judicialização, no Brasil, surge como o resultado de um processo de ampliação das políticas regulatórias, criadas num contexto de aceleração do desenvolvimento industrial e urbano, durante o governo de Getúlio Vargas, que teve início em 1930. A expansão da máquina administrativa estatal permitiu a elaboração de políticas que visavam à efetivação dos direitos sociais. Como esse processo se deu por meio do corporativismo, numa prática de cooptação dos trabalhadores, a possibilidade da formação de organizações autônomas foi obstruída, enquanto o exercício do controle estatal tornara-se mais efetivo. No entendimento de Lafer (1988), o intervencionismo estatal posterior a crise de 1929 exacerbou o processo de positivação do direito pelo Estado, de modo que o direito tornara-se menos coercitivo, passando a servir como instrumento de gestão da sociedade ${ }^{4}$. Desde então, o Poder Judiciário deixou de representar apenas os interesses da burguesia, podendo ser acionado também pelos trabalhadores.

Com a crise do Estado de bem-estar nos países desenvolvidos, muitas críticas foram dirigidas às formas estatais de controle, enfatizando a ideia de que suas instituições funcionavam como aparelhos ideológicos, servindo antes aos interesses do Estado do que a cidadania. Alegava-se a falta de espaço para a autonomia, assim como o impedimento à possibilidade de exercício de uma cidadania ativa, que pudesse servir como fonte do poder social. Com a finalidade de alterar esta situação, o tema do direito adquiriu destaque trazendo simultaneamente uma reflexão sobre o papel do Poder Judiciário. Com as duas grandes guerras e a experiência dos regimes autoritários, o interesse em limitar as ações do Poder Executivo adquiriram relevo de tal modo, que os movimentos sociais se voltaram à intenção de fazer com que os direitos humanos não ficassem restritos à mera declaração, mas que fossem assegurados por mecanismos jurisdicionais.

No Brasil, buscou-se inserir no direito mecanismos que garantissem a sua efetivação, de modo que o governo pudesse ser julgado pela violação ou omissão, todas as vezes que assumisse posição contrária às cláusulas constitucionais. O movimento pelo aces- so à justiça, diferentemente do que acontecia em outros países - que buscavam alternativas de acesso aos tribunais - expressava a preocupação com a garantia da efetivação dos direitos coletivos e difusos $^{5}$. A Constituição de 1988 atendeu a esta demanda ao incorporar recursos, como a ação civil pública $^{6}$, o mandado de segurança ${ }^{7}$, o mandado de injunção ${ }^{8}$, que podem ser utilizados para pressionar o governo a executar medidas em favor do cumprimento da lei. Por conseguinte, a elaboração de diplomas normativos, ainda que se possa considerar a falta de condições do Estado para observação das normas, tem como efeito o estreitamento da relação entre os juízes e a política. Atualmente, o Poder Judiciário está sendo cobrado da função de avaliar se as determinações do Poder Executivo estão em consonância com as leis. Esta mudança incide diretamente sobre os juízes, que precisam abdicar da postura de "funcionários do governo", como entendia Montesquieu, para atuar como atores políticos.

Entre outros motivos, este processo tem sido questionado porque o exercício da cidadania mediante o acesso ao Poder Judiciário nem sempre é percebido como parte do processo político democrático. Críticas são feitas a sua intromissão na política, sob o argumento de que é a esfera pública o espaço legítimo para participação. Nesta perspectiva, entende-se que a cobrança pelo direito ao se dirigir ao Poder Judiciário, descaracteriza a identificação da questão enquanto problema coletivo, enraizado na luta de classe, que tem como efeito o esvaziamento da participação em outros espaços. Tal análise, ao desprezar o fato de que partidos, sindicatos e associações tem a chance de atuar como intérpretes da Constituição por meio do ajuizamento de ações, não confere relevância ao envolvimento do Poder Judiciário nos processos de deliberação política.

Zaffaroni (1993), ao perceber a resistência ao reconhecimento da independência do Poder Judiciário na América Latina, considera não haver devido entendimento acerca de sua importância pelas organizações políticas, pois enquanto a direita expressa interesse pela sua manipulação, a esquerda busca depreciálo. Ao considerar esta uma problemática central em nossas democracias, o autor afirma que:

Ante la falta de una jurisdicción que imponga minimamente la supremacía constitucional y que opere con cierto grado de eficácia en la decisión y solución de conflictos, cada vez serán menos los obstáculos al ejercicio arbitrario del poder, las mayorías coyunturales y los políticos se burlaran cada dia mas de los limites constitucionales a su poder, no habrá un acotado espacio de juego democrático, sino una selva de disputas con cualquier medio y a cualquier precio, la demagogia y la irracionalidad triunfarán cada día mas 
sobre la racionalidad y la serenidad, y nuestras débiles democracias serán cada día más dictaduras en envase democrático (ZAFFARONI, 1993, p. 19).

A fim de que a Constituição não passe de uma referência utópica, incapaz de impedir o autoritarismo e de limitar a vontade da maioria, a ideia da neutralidade do Poder Judiciário foi abandonada, passando a ser admitida a participação de representações funcionais na política (juízes, promotores, conselheiros), que retiram sua legitimidade do processo de institucionalização dos direitos humanos. Decerto que este processo não ocorre sem efeitos perversos, mas ainda que se considere a judicialização das políticas como um dano as democracias, a possibilidade de acionar a justiça não deixa de ser um recurso à cidadania que, ao contrário do que se presume, não provoca a despolitização da sociedade, mas tem por efeito a politização da justiça. Segundo Cittadino (2004, p. 110),

A própria Constituição de 1988 instituiu diversos mecanismos processuais que buscam dar eficácia aos seus princípios e essa tarefa é responsabilidade de uma cidadania juridicamente participativa que depende, é verdade, da atuação dos tribunais, mas, sobretudo, do nível de pressão e mobilização política que, sobre eles, se fizer.

Apesar destas considerações, é importante destacar as implicações da política neoliberal sobre o fenômeno da judicialização. A Constituição de 1988, ao adotar o constitucionalismo dirigista ou de caráter social, que foi iniciado na Constituição mexicana de 1917 e na Constituição de Weimar de 1919, visava organizar um Estado que se voltasse à promoção do bem-estar social, ao contrário das constituições liberais que buscavam assegurar a liberdade do mercado (VIEIRA, 1997, p. 59). Segundo Cittadino (1999), esta Constituição ao estabelecer as bases do Estado de direito, procurou reunir pluralismo com justiça distributiva. Não obstante a expressão deste novo ideal de justiça social, a década seguinte não tardou em apresentar as contradições que envolvem o direito e a política no Brasil. Durante a década de 1990, apesar da crescente elaboração de normas e estatutos, as medidas neoliberais, adotadas pelos governos, acabaram debilitando a classe trabalhadora, ao permitir o aumento do desemprego, o enfraquecimento dos sindicatos e a degradação da proteção social. Por efeito, a demanda ao Poder Judiciário aumentou, trazendo aos juízes a cobrança dos cidadãos pelo cumprimento de seus direitos.

De acordo com o pensamento de Vianna, Burgos e Salles (2007), a procura pelo Poder Judiciário no Brasil é uma alternativa para aqueles que buscam proteção social, num contexto de avanço da política neoliberal, de enfraquecimento dos sindicatos e da vida associativa. Para Vianna, Burgos e Salles (2007, p. 41),

\begin{abstract}
A invasão do direito sobre o social avança na regulação dos setores mais vulneráveis, em um claro processo de substituição do Estado e dos recursos institucionais classicamente republicanos pelo judiciário, visando a dar cobertura à criança e ao adolescente, ao idoso e aos portadores de deficiência física. O juiz torna-se protagonista direto da questão social. Sem política, sem partidos ou uma vida social organizada, o cidadão volta-se para ele, mobilizando o arsenal de recursos criado pelo legislador a fim de lhe proporcionar vias alternativas para a defesa e eventuais conquistas de direitos.
\end{abstract}

No Brasil, o processo de judicialização tem se realizado em meio a conflitos que envolvem a sociedade, o Poder Executivo e o Poder Judiciário. A produção teórica do Serviço Social tem se voltado para o tema de forma crítica, dando ênfase aos aspectos negativos. Em geral, destaca-se o avanço do neoliberalismo e a consequente destituição dos direitos sociais como agravantes ao processo de judicialização. Nestes termos, a demanda por proteção social, que tem engrossado os processos no Poder Judiciário, identifica-se como a judicialização da questão social, tida como algo que ocorre em "detrimento do compromisso mais efetivo do Estado e da esfera pública" (AGUINSKI; ALENCASTRO, 2006, p. 20). As autoras ainda consideram que o fenômeno envolve um processo de despolitização dos conflitos de classe, visto que as demandas não são compreendidas coletivamente, mas tomadas individualmente, sendo resolvidas caso a caso. Além disso, o destaque ao Poder Judiciário se faz ao salientar as dificuldades de acesso às classes populares, a falta de celeridade e ao formalismo excessivo.

Apesar de reconhecer a importância da participação do Poder Judiciário na luta pela afirmação e reconhecimento da cidadania, Iamamoto (2004, p. 280) segue na mesma direção, demonstrando receio por entender que, enquanto parte do poder do Estado, o Poder Judiciário "também carrega fortes marcas do saber burocrático, próprio dos aparelhos estatais, o que se espraia na cultura das repartições públicas e de seus agentes, que pode impregnar os profissionais que aí atuam.'”

Outros trabalhos na linha dos direitos humanos que enfatizam o aumento da legislação e do Poder Judiciário, produzidos pelo Serviço Social, realizam críticas relacionadas ao endurecimento das penas e à ampliação do controle social, exercido pelos Juizados Criminais, Juizados da Violência Doméstica e Familiar contra a Mulher, Juizados da Infância, da Juventude e do Idoso, Varas de Família e Conselhos Tutelares ${ }^{9}$. Alega- 
se que, em parte, essas instituições favorecem a adaptação do modelo penal (WACQUANT, 2001) no Brasil, que é imposto às classes populares num contexto de deterioração das políticas sociais, desencadeando o processo de criminalização da pobreza.

De fato, mais do que uma forma de proteção contra os abusos do Poder Executivo, a judicialização da política pública, no Brasil, ocorre em função da escassez de políticas que assegurem a efetivação dos direitos de cidadania. De certo modo, não é sobre o reconhecimento da autonomia do sujeito ou da exigência por participação no controle social que aumentam os processos judiciais, mas é da cobrança pelo acesso aos serviços públicos, principalmente, de saúde, educação e assistência. Muitos desses processos são ajuizados na expectativa de que os juízes forcem o governo a cumprir o direito.

Desde as duas últimas décadas, a atividade judicial tem se expandido e se destacado pelo aumento de sua intromissão na política e nas relações sociais. Os juizados especiais ampliaram o acesso à justiça e contribuíram no processo de "desformalização"dos processos, tornando o juiz mais próximo da sociedade, num trabalho de valorização da cidadania, como é o caso da defesa dos direitos do consumidor. Por outro lado, nos casos de distribuição de medicamentos e do Benefício da Prestação Continuada (BPC), a magistratura tem expressado um novo comportamen-

mais do que uma forma de

proteção contra os abusos do Poder Executivo, a judicialização da política pública, no Brasil, ocorre em função da escassez de políticas que assegurem a efetivação dos direitos de cidadania. to, passando a fundamentar suas sentenças a partir da interpretação da Constituição. Esse processo tem gerado controvérsias, principalmente na saúde, devido aos problemas que incorrem sobre a administração do orçamento (CHIEFFI; BARATA, 2009). Nas ações judiciais, visando o direito ao BPC, a disputa chega até a última instância do Poder Judiciário. Ao analisar essa temática, Santos (2009, p. 93) considera que a judicialização do BPC tem provocado o questionamento dos critérios de elegibilidade dos benefícios, propondo aperfeiçoamentos para a política. Em seu entendimento, a "judicialização pode ser interpretada também como um momento em que o fortalecimento do Poder Judiciário tem relação direta com o fortalecimento dos direitos humanos."

Em resumo, é possível afirmar que se a judicialização pode ser percebida como um "sintoma" das democracias contemporâneas, que se encontram em estado de anomia, conforme o pensamento de Garapon (1999), num outro sentido ela coloca em xeque a formação jurídica dos magistrados, a tradição formalista do Poder Judiciário e dissemina na sociedade a linguagem do direito, servindo como referência à cidadania. Atualmente, o Poder Judiciário tem sido levado a refletir acerca das mudanças que podem ser implementadas, passando a assumir uma maior responsabilidade com o "social". Daí a importância do conhecimento dos tratados, convenções, protocolos e instrumentos internacionais, que, juntamente com as leis e estatutos nacionais, podem servir para fundamentar as sentenças judiciais, oferecendo à magistratura a possibilidade de se tornar mais sensível aos problemas sociais. Nos casos dos medicamentos e do BPC, por exemplo, os juízes têm confrontado a "razão do Estado" passando a cobrar do governo a efetivação dos direitos definidos na Constituição. Nesse sentido, a judicialização tem expressado a insatisfação pela insuficiência de políticas públicas. Todavia, como todo processo no capitalismo tem seu lado obscuro, o protagonismo do Poder Judiciário

na questão do acesso aos serviços e aos bens públicos, ao surtir o efeito desejado, tende a provocar mudanças no comportamento social, de tal modo que a justiça pensada como última alternativa passa a ser percebida como a única esperança de solução. A judicialização revela-se, assim, um fenômeno ambíguo, pois se a corrida ao Poder Judiciário pode significar o aumento da pressão social por serviços, ela ao mesmo tempo tende a colocar em risco a autoridade da justiça, caso suas decisões não venham a ser acatadas. A questão não é simples, mas é de primordial importância para o assistente social que também é parte neste trabalho de garantia dos direitos de cidadania.

\section{Os assistentes sociais no sociojurídico e a judicialização da questão social}

A Constituição de 1988, ao definir a assistência como um dos pilares da Seguridade Social, serviu à sua compreensão como direito social. Quando as queixas dos usuários desse sistema chegam ao Poder Judiciário, os assistentes sociais são convocados a realizar o laudo técnico, informando acerca das condições que poderão ser enquadradas nas normas de concessão do direito. Considerando que os problemas relacionados com a assistência extrapolam o âmbito judicial, os juízes precisam recorrer ao suporte de uma equipe multidisciplinar, que conta com profissionais da pedagogia, da psicologia e do Serviço Social. 
A inserção do assistente social no Poder Judiciário iniciou-se nos anos 1940, mas a configuração do campo sociojurídico só ocorreu de maneira expressiva a partir da década de 1990, quando o saber desse profissional passou a ser mais frequentemente requisitado no sistema do Poder Judiciário. De fato, muitas mudanças foram introduzidas no direito, ampliando de forma significativa o que fora conhecido como a "clientela da justiça", passando a requerer do assistente social um conhecimento maior das legislações sociais. Nessa perspectiva, o Serviço Social ampliou sua esfera de ação com a ampliação do campo sociojurídico, que segundo Valente (2008, p. 99) é formado por: Varas de Infância, Juventude e Família, Órfãos e Sucessões, Execuções Penais, Central de Penas Alternativas, Ministério Público, Delegacias de Polícia especializadas, Defensorias Públicas, Escritórios de Práticas Jurídicas e, ainda, instituições que aplicam medidas protetivas (abrigos) ou socioeducativas (adolescentes infratores), presídios, Conselhos Tutelares e Conselhos de Direitos. Apesar do campo sociojurídico não estar circunscrito ao Poder Judiciário, o processo de trabalho dos assistentes sociais que atuam nele realiza-se mediante a referência da autoridade judicial, o que faz com que esses profissionais sejam absorvidos no processo de judicialização da questão social. Segundo Valente (2008, p. 94), trata-se de um desafio a ser enfrentado pelos assistentes sociais que atuam no Poder Judiciário:

Eis o desafio dos assistentes sociais do judiciário, nestes tempos de expansão de direitos e recrudescimento do Estado. Desafio que vai além dos aspectos técnicos e que também não se esgotam nos fatores socioeconômicos. Além de compreenderem a avalanche de transformações sociais por que passa a família, nas últimas décadas, é preciso que os assistentes sociais estejam atentos à relação mais ampla entre o Estado e a sociedade, bem como a atual reconfiguração do judiciário.

Como profissional que lida diretamente com as expressões da questão social, os estudos e pareceres do assistente social são instrumentos imprescindíveis ao trabalho de assessoria aos juízes. Por refletir acerca das questões conjunturais e estruturais que incidem sobre as desigualdades sociais, a inserção do assistente social no Poder Judiciário contribui no sentido de proporcionar a aproximação do jurídico da consideração com as condições de existência dos indivíduos. Segundo Souza (2006, p. 68),

A busca da 'verdade jurídica dos fatos' (no seu caráter absoluto) subordina-se, em certa medida, às verdades parajurídicas dos fatos (no seu caráter relativo, dinâmico e histórico) apreendidas no processo de estudo, problematização, análise e avaliação das expressões da questão social que podem interferir (ou estão interferindo) na resolução dos conflitos judicializados no âmbito da primeira instância.

De acordo com Trindade e Soares (2009, p. 2), o assistente social exerce certo poder ao influenciar os operadores do direito, com suas avaliações e estudos. Trata-se de um poder profissional que "se expressa na sua capacidade de avaliar, de julgar ao emitir um parecer com uma sugestão ao opinar sobre um caso, tendo um grande peso nos julgamentos judiciais." Este serviço não se restringe ao âmbito burocrático, necessitando, assim, do reconhecimento de sua dimensão ética.

Convém ressaltar que os assistentes sociais dispõem de autonomia técnica no exercício de suas atribuições no Poder Judiciário (Lei n. 8.662/93, CRESS, 1993), mesmo estando subordinados legalmente e institucionalmente aos juízes. Este serviço, ora é reconhecido como uma prática de exercício do controle social do Estado, no sentido de conferir legitimidade às suas ações; ora é percebido de maneira mais positiva, como uma possibilidade de defesa dos direitos de cidadania. Em seu artigo sobre a participação do assistente social na judicialização dos conflitos nos Tribunais de Justiça do Distrito Federal e Territórios, Souza (2006, p. 71) considera que as Varas de Família e da Infância constituem o lócus privilegiado de averiguação, policiamento e imposição, sendo, portanto, lócus privilegiado de atuação do assistente social. Todavia, Souza (2006, p. 77) ressalta que a diferença do trabalho do assistente social com relação aos outros profissionais é que ele se efetua numa "perspectiva de consolidação, garantia e ampliação de direitos, o que implica acolhimento e escuta profissional."

De acordo com Souza (2006, p. 78), o trabalho do assistente social no Poder Judiciário apresenta caráter mediador e contraditório. Esta afirmação baseia-se na consideração de que a mediação é fundamental para a viabilização do acesso aos bens e serviços, muitas vezes negados em outras instâncias. Contudo, o autor entende que a realização desse trabalho produz efeito negativo, tendo em vista o fato de que "a adequação dos conflitos à esfera do direito normativo acaba despolitizando, individualizando e particularizando as expressões da questão social, cuja base encontra-se na conjuntura e estrutura sócio-histórica da sociedade brasileira." Santos (2009), assim como outros assistentes sociais, percebe o processo de judicialização não como um recurso ao cidadão, mas como um impasse à participação democrática. Um passado marcado por positivismo jurídico, lentidão, rigidez hierárquica, excessos burocráticos e desconsideração, que, ainda presentes de parte de alguns magistrados em determinados casos de violação dos direitos humanos, reforçam a descrença na capacidade do Poder Judiciário de se voltar à defesa da cidadania. 
Reis (2010, p. 172) tem uma análise mais favorável ao fenômeno e à atuação do Serviço Social nos Juizados Especiais Federais. A autora comenta que, segundo dados do Serviço Social da Seção de Atendimentos Processuais dos Juizados Especiais (Sapje), $40 \%$ dos casos atendidos no setor são resolvidos com encaminhamento formal às instituições externas, principalmente ao Instituto Nacional do Seguro Social (INSS) e às unidades de saúde. Significa, então, que nem tudo que entra nos juizados chega até o juiz, podendo o Serviço Social realizar as mediações neste processo.

Segundo Souza (2004, p. 127), o diferencial da participação do assistente social nas instituições judiciárias provém de sua capacitação por seus "conhecimentos e habilidades teórico-metodológicos, técnico-operativos e ético-políticos". Neste sentido, a prática profissional dos assistentes sociais no sociojurídico deve seguir a direção do Projeto Ético-Político, bem como as determinações do Código de Ética Profissional, que define como princípios fundamentais:

[...] o reconhecimento da liberdade como valor ético central e das demandas políticas a ela inerentes - a emancipação e plena expansão dos indivíduos sociais; a defesa intransigente dos direitos humanos e recusa ao arbítrio do autoritarismo e a ampliação e consolidação da cidadania, considerada tarefa primordial de toda sociedade, com vistas à garantia dos direitos civis sociais e políticos das classes trabalhadoras (CFESS, 1993, on-line).

\section{Considerações finais}

A judicialização da política é um fenômeno que recusa a submissão da democracia ao princípio da regra majoritária, conferindo papel ativo ao Poder Judiciário na defesa da cidadania, pelo reconhecimento das identidades sociais. Trata-se de um processo contraditório que avança com a expansão da atividade judicial e o declínio das políticas sociais. Portanto, se hoje assistimos a uma invasão da sociedade na justiça, isso ocorre porque o Poder Executivo tem se negado a assumir a responsabilidade com a efetivação dos direitos, conforme consta na nossa Constituição e nas leis infraconstitucionais. Nessas condições, é possível entender que o esforço no sentido da democratização do acesso à justiça representa uma alternativa por onde as queixas dos cidadãos podem ser atendidas. Mesmo considerando que as demandas chegam ao Poder Judiciário em geral individualmente, nada impede que as organizações da sociedade civil venham fazer uso das ações civis públicas como forma de pressionar o governo pela efetivação de direitos. Ainda que não seja este um espaço tradicional para a luta política, a corrida ao Poder Judiciário não impede a manifestação de outras formas de participação no espaço público. Afinal, quem garante que a sociedade seria politicamente mais organizada e atuante na ausência deste recurso?

Por fim, é possível afirmar que a judicialização da questão social compreende dois movimentos, visto que, se por um lado, expressa o avanço no sentido do aumento do controle, levando à criminalização da pobreza, por outro, amplia a possibilidade de fazer com que a "superestrutura ideológica do Estado" não funcione para atender exclusivamente aos interesses da classe dominante. Desse modo, a relevância para o Serviço Social se faz por sua contribuição na tarefa de tornar a justiça mais substantiva. Trata-se de um trabalho com implicações éticas, pois ao mesmo tempo em que se inclina em defesa da cidadania, numa perspectiva promocional do direito, também serve ao aperfeiçoamento dos mecanismos de controle social, permitindo a aplicação do direito como técnica de gestão. De um modo ou de outro, é sobre a questão social que está se debruçando ao realizar um trabalho relevante de assessoria aos juízes. Estes já não se restringem a punir os pobres, mas começam a fundamentar suas sentenças articulando o parecer do Serviço Social com uma interpretação dos direitos fundamentais definidos na legislação.

\section{Referências}

AGUINSKI, B. G.; ALENCASTRO, E. H. Judicialização da questão social: rebatimentos nos processos de trabalho dos assistentes sociais no Poder Judiciário. Revista Katálysis, Florianópolis: Edufsc, v. 9, n. 1, p. 19-26, jan./ jun. 2006.

BRASIL. Constituição da República Federativa do Brasil. Promulgada em 5 outubro de 1988. São Paulo: Atlas, 1999.

CFESS-Conselho Federal de Serviço Social. Código de Ética Profissional dos Assistentes Sociais. 1993. Disponível em: <http://www.cfess.org.br/pdf/legislacao etica cfess.pdf>. Acesso em: 12 jan. 2011.

CHIEFFI, A. L.; BARATA, R. B. Judicialização da política pública de assistência farmacêutica e equidade. Cadernos de Saúde Pública, Rio de Janeiro, v. 25, n. 8, p. 1839-1849, ago. 2009.

CITTADINO, G. Poder Judiciário, ativismo judiciário e democracia. Revista Alceu, Rio de Janeiro, v. 5, n. 9, p. 105113, jul./dez. 2004.

Pluralismo, Direito e Justiça Distributiva. Rio de Janeiro: Lumen Juris, 1999. 
CRESS-Conselho Regional de Serviço Social. Lei 8.662/93, dispõe sobre a profissão do Serviço Social. Disponível em: http://www.cressrs.org.br/index.asp?page $=$ areas.asp\&numgif=1\&id=1>. Acesso em: 12 jan. 2011.

FRASER, N. A justiça social na globalização: redistribuição, reconhecimento e participação. Revista Crítica de Ciências Sociais, Portugal, n. 63, p. 7-20, out. 2002.

GARAPON, A. O juiz e a democracia. Rio de Janeiro: Revan, 1999.

IAMAMOTO, M. V. Questão Social, família e juventude: desafios do trabalho do assistente social na área sociojurídica. Prefácio. São Paulo: Cortez, 2004.

JUNQUEIRA, E. B. Acesso à Justiça: um olhar retrospectivo. Revista Estudos Históricos, CPDOC/FGV, Rio de Janeiro, v. 9, n. 18, 1996.

LAFER, C. Reconstrução dos direitos humanos: um diálogo com o pensamento de Hannah Arendt. Rio de Janeiro: Companhia das Letras, 1988.

REIS, J. F. dos. Nos caminhos da judicialização-um estudo sobre a demanda judicial pelo Benefício da Prestação Continuada. Dissertação (Mestrado em Política Social) Universidade Federal Fluminense, Rio de Janeiro, 2010.

SANTOS, W. R. dos. Deficiência e democracia: a interpretação do Poder Judiciário sobre o Benefício da Prestação Continuada. Dissertação (Mestrado em Política Social) - Universidade de Brasília, Brasília, DF, 2009.

SOUZA, M. F. A participação do assistente social na judicialização dos conflitos sociais. Ser Social, Brasília, n. 19, p. 59-83, jul./dez. 2006.

Condições, determinações e particularidades do processo de trabalho do assistente social nos órgãos do Poder Judiciário sediados em Brasília. Dissertação (Mestrado) - Universidade de Brasília. Departamento de Serviço Social, Brasília, DF, 2004.

TRINDADE, R. L. P.; SOARES, A. C. F. Saber e poder profissional do assistente social no campo sociojurídico In: CONGRESSOBRASILEIRODE SOCIOLOGIA, 14.29 a 31 de julho de 2009, Rio de Janeiro, 2009.

VALENTE, M. L. C. S. O Serviço Social e a expansão do judiciário: uma reflexão introdutória. O Social em Questão, PUC, Rio de Janeiro, Departamento de Serviço Social, v.15, n. 15 , p. $92-116,2008$.

VIANNA, L. W.; BURGOS, M. B.; SALLES, P. M. Dezessete anos de judicialização da política. Tempo Social, Revista de Sociologia da USP, São Paulo, v. 19, n. 2, p. 39-85, 2007.
VIEIRA, O. V. A Constituição como reserva de justiça. Lua Nova, Revista de Cultura e Política, Cedec, São Paulo, n. 42, p. 53-97, 1997.

WACQUANT, L. Punir os pobres: a nova gestão da miséria nos Estados Unidos. Rio de Janeiro: Instituto Carioca de Criminologia Freitas Bastos, 2001.

ZAFFARONI, E. R. Dimensión política de un Poder Judicial democrático. Cuadernos de Derecho Penal. 1993. Disponível em: <http://www.pensamiento penal.com.ar/51zaffaroni.pdf $>$. Acesso em: 12 jan. 2011.

\section{Notas}

1 A Constituição instituiu o controle abstrato de normas (art. 103, I ao X), o controle omissivo de inconstitucionalidade (art. 103, $\S 2^{\circ}$ ) e estabeleceu a possibilidade da instituição da arguição de descumprimento de preceito fundamental (art. $\left.102, \S 1^{\circ}\right)$.

2 Doutrina que substituiu a ideia da relação harmoniosa entre os Poderes, conforme pensada por Montesquieu, pela concepção de democracia que autoriza o controle de um Poder sobre o outro. Ao conferir papel ativo ao Poder Judiciário, esse modelo, que foi criado pelos americanos, desenvolveu um sistema de pesos e contrapesos conhecido como checks and balances.

3 Sobre políticas de reconhecimento, ver Fraser (2002).

4 Segundo Lafer (1988, p. 45), da função de qualificar a conduta como ética ou boa, o direito passou também a servir como instrumento de gestão da sociedade.

5 Segundo Junqueira (1996), ao contrário do que vinha acontecendo nos países centrais, no caso brasileiro não se tratava, pelo menos no início dos anos 1980, de buscar procedimentos jurídicos mais simplificados e alternativas aos tribunais como meio de garantir o acesso à Justiça e de diminuir as pressões resultantes de uma explosão de direitos que ainda não havia acontecido. Ao contrário, tratava-se, fundamentalmente, de analisar como os novos movimentos sociais e suas demandas por direitos coletivos e difusos, que ganharam impulso com as primeiras greves do final dos anos 1970 e com o início da reorganização da sociedade civil que acompanharam o processo de abertura política, poderiam lidar com um Poder Judiciário tradicionalmente estruturado para o processamento de direitos individuais.

6 De acordo com a Lei n. 7.347, de 24 de julho de 1985, a ação civil pública é a ação que tem por objetivo responsabilizar por danos morais e patrimoniais causados ao meio ambiente, ao consumidor, à ordem urbanística, a bens e direitos de valor artístico, estético, histórico, 
turístico e paisagístico, a interesse difuso ou coletivo, por infração da ordem econômica e da economia popular.

7 O mandado de segurança é uma ação constitucional contra atos de autoridade pública ou agente de pessoa jurídica, considerados ilegais ou abusivos (BRASIL, 1988, Artigo 5 inciso LXIX).

8 De acordo com a Constituição de 1988, "conceder-se-à mandado de injunção sempre que a falta de norma regulamentadora torne inviável o exercício dos direitos e liberdades constitucionais e das prerrogativas inerentes à nacionalidade, à soberania e à cidadania" (BRASIL, 1988, Artigo $5^{\circ}$, inciso LXXI).

9 Segundo matéria do Jornal do Brasil, de 11 de março de 2011, ainda não há um juizado especializado no combate ao crime contra a mulher em cada estado brasileiro, sendo os casos atendidos nos juizados criminais existentes. No caso dos direitos da criança e do adolescente, os juizados também podem não ser exclusivos, acumulando as ações ligadas ao direito dos idosos ou ao direito de família, o que provoca variação nos nomes desses juizados.

\section{Vânia Morales Sierra}

vaniasierra@yahoo.com.br

Doutora em Sociologia pelo Instituto Universitário de Pesquisa do Estado do Rio de Janeiro (Uperj)

Professora adjunta na Faculdade de Serviço Social da Universidade do Estado do Rio de Janeiro (FSSUERJ)

\section{UERJ - Faculdade de Serviço Social}

Rua São Francisco Xavier, 524

Maracanã - Rio de Janeiro

CEP: 20559-900 